Corrigendum

\title{
Corrigendum to "Tabu Search and Machine-Learning Classification of Benign and Malignant Proliferative Breast Lesions"
}

\author{
Habib Dhahri $\mathbb{D}^{1,2}$ Ines Rahmany $\mathbb{D}^{1},{ }^{2}$ Awais Mahmood $\mathbb{D},{ }^{1}$ Eslam Al Maghayreh $\left(\mathbb{D},{ }^{1,3}\right.$ \\ and Wail Elkilani ${ }^{1}$ \\ ${ }^{1}$ College of Applied Computer Sciences (CACS), Al-Muzahimiyah Branch, King Saud University, Riyadh, Saudi Arabia \\ ${ }^{2}$ Faculty of Sciences and Technology of Sidi Bouzid, University of Kairouan, Kairouan, Tunisia \\ ${ }^{3}$ Computer Science Department, Yarmouk University, Irbid, Jordan
}

Correspondence should be addressed to Habib Dhahri; hdhahri@ksu.edu.sa

Received 7 June 2020; Accepted 17 June 2020; Published 10 July 2020

Copyright (C) 2020 Habib Dhahri et al. This is an open access article distributed under the Creative Commons Attribution License, which permits unrestricted use, distribution, and reproduction in any medium, provided the original work is properly cited.

In the article titled "Tabu Search and Machine-Learning Classification of Benign and Malignant Proliferative Breast Lesions" [1], author Dr. Eslam Al Maghayreh was not affiliated to "College of Applied Computer Sciences (CACS), Al-Muzahimiyah Branch, King Saud University, Riyadh, Saudi Arabia" which is incorrect. The corrected list of affiliations is shown in the author information above.

\section{References}

[1] H. Dhahri, I. Rahmany, A. Mahmood, E. Al Maghayreh, and W. Elkilani, "Tabu search and machine-learning classification of benign and malignant proliferative breast lesions," BioMed Research International, vol. 2020, 10 pages, 2020. 